\title{
A non-destructive NIR spectroscopic method combined with chemometry for simultaneous assay of paracetamol and caffeine in tablets
}

\author{
Dana MUNTEAN, Alina PORFIRE, Cristian ALECU, Sonia IURIAN, Tibor CASIAN, \\ Alexandru GAVAN, Ioan TOMUTA \\ Department of Pharmaceutical Technology and Biopharmacy, "Iuliu Hatieganu" University of Medicine and \\ Pharmacy, Cluj-Napoca, Romania
}

\begin{abstract}
The use of near infrared (NIR) spectroscopy to predict the concentration of two active pharmaceutical ingredients (APIs), paracetamol and caffeine, in intact tablets, has been evaluated in this study. A partial least squares (PLS) regression model was developed using spectral data obtained on a calibration set consisting of 28 formulations containing 80, 90, 100, 110 and 120\% of each API. Regression models were developed for each API, both using un-processed spectral data as well as after applying various spectra pre-processing methods. Cross-validation was used to select best calibration model. The selected model was validated in terms of precision, trueness, accuracy and linearity in a concentration ranging from 90 to $110 \%$ of the targeted APIs concentration. The applicability of the method was tested on tablets containing $300 \mathrm{mg}$ paracetamol and $30 \mathrm{mg}$ caffeine as targeted composition, and the API content predicted by the proposed NIR-chemometric method was not statistically different from the one obtained by HPLC method, used as a reference method. Thus, the method presented in the current paper is a step forward towards the implementation NIR as useful tool for monitoring the manufacturing process of fixed-dose combination tablets with paracetamol and caffeine.
\end{abstract}

Keywords: NIR spectroscopy, chemometry, paracetamol, caffeine, tablets, API assay

\section{INTRODUCTION}

Tablets containing paracetamol and caffeine are used for the temporary relief of pain, being available as fixed-dose combination products. The content of the active substances in these products is routinely determined by HPLC, a time-consuming, destructive method, involving the use of many organic solvents. In the latest years, near infrared (NIR) spectroscopy has been increasingly used in pharmaceutical development and drug manufacturing, due to its non-destructive characteristics, low cost and low time for analysis [1]. For the same advantages, this method has been recognised by the European Directorate for the Quality of Medicines, which introduced in 2014 a dedicated monograph in the European Pharmacopoeia [2]. According to this, NIR 
spectroscopy has applications in chemical analysis (identification, qualification and quantification of active substances, excipients, manufacturing intermediates, etc.), physical analysis (crystalline form, polymorphism, disintegration, hardness, etc.) and process analysis.

NIR spectroscopy has been described in literature as a useful tool for characterisation of a wide range of pharmaceutical dosage forms, including solid dosage ,forms - powders, granules, tablets, coated tablets $[3,4,5,6,7,8]$, and liquid dosage forms - solutions, syrups, nanoformulations $[9,10,11,12]$. The NIR spectrum contains information related to both, chemical and physical characteristics of the analysed sample, so NIR spectroscopic methods are a source of multivariate data and chemometric methods are required for qualitative and quantitative applications [13].

In this paper, an approach based on combining NIR spectroscopy with multivariate calibration was exploited to directly and simultaneously quantify caffeine and paracetamol in tablets. The same approach has been described before by other authors, to develop rapid and reliable methods for chemical characterisation of tablets. For example, a group of authors developed a NIR spectroscopic method for simultaneous assay of amlodipine and valsartan in immediate release tablets, and evaluation of content uniformity [14 ]. Another paper reports the development and validation of a NIR spectroscopic method based on multivariate calibration for simultaneous determination of four drugs, i.e. pyrazinamide, isoniazid, rifampicin and ethambutol, allowing the quality control of tablets employed in tuberculosis treatment with for drugs [15]. Some works dealing with the chemical characterisation of tablets by NIR spectroscopy report the simultaneous assay of active ingredient and excipients $[16,17,18]$. Besides chemical characterisation, some papers report the simultaneous determination of physical and pharmaceutical properties of tablets by NIR, such as hardness, disintegration time and drug dissolution $[19,20,21,22,23]$.

We have reported in a previous work the development and validation of a NIR-chemometric method as a suitable tool for prediction of paracetamol and caffeine in the powder blend for tabletting, in view to determine the blend uniformity during mixing steps of the manufacturing process [24]. As the trend in pharmaceutical manufacturing nowadays is to move from batch processing toward continuous processing, the development of suitable methods for rapid quality monitoring of the product in each step of the production process is necessary. Thus, the method presented in the current paper is a step forward towards the implementation NIR as useful tool for monitoring the manufacturing process of fixed-dose combination tablets with paracetamol and caffeine.

\section{MATERIALS AND METHODS}

\section{Materials}

Paracetamol was obtained from Novacyl, France and anhydrous caffeine was from BASF, Germany. All the used excipients were pharmaceutical grade: cornstarch (Roquette, France), polyvinyl-pyrrolidone (PVP) (BASF, Germany), lactose monohydrate Tablettose 80 (Meggle, Germany). colloidal silicon dioxide - Aerosil (Rohm Pharma Polymers, Germany), magnesium stearate (Union Derivan S.A, Spain) and talc (IMERYS Luzenac, France). Al the reagents used in reference methods were of analytical grade.

\section{Tablets manufacturing}

Immediate release tablets with paracetamol (300 mg/ tablet) and anhydrous caffeine (30 mg/tablet) as active pharmaceutical ingredients (APIs) were prepared by wet granulation followed by compression, as previously described [24]. The tablets compression was carried out using an eccentric tablet press EK-0 (Korsch, Germany), equipped with a $13 \mathrm{~mm}$ set of punches and die. The tablet weight was set at $620 \mathrm{mg}$. The powder blend for tabletting containing $4.84 \%$ $(\mathrm{w} / \mathrm{w})$ caffeine and $48.38 \%(\mathrm{w} / \mathrm{w})$ paracetamol was considered as $100 \%$ active content formulation or targeted tablet composition.

\section{Calibration and validation protocol}

In table 1 are presented the composition of the tablets prepared for calibration and validation purpose.

In order to predict the caffeine and paracetamol content of tablets, an orthogonal experimental design with two factors and five levels was used to generate the calibration set. Modde 11.0 software (Umetrics, Sweden) was used to develop the experimental design. The factors used were paracetamol amount (X1; $\mathrm{mg} /$ tablet) and caffeine amount (X2; $\mathrm{mg} /$ tablet). The $\mathrm{X} 1$ and $\mathrm{X} 2$ levels were varied between $80 \%$ and 
TABLE 1. Calibration and validation samples composition

\begin{tabular}{|c|c|c|c|c|c|}
\hline \multirow{2}{*}{$\begin{array}{l}\text { Concentration } \\
\text { Level }\end{array}$} & 1 & 2 & 3 & 4 & 5 \\
\hline & $80 \%$ & $90 \%$ & $100 \%$ & $110 \%$ & $120 \%$ \\
\hline Paracetamol & 38.71 & 43.55 & 48.39 & 53.23 & 58.06 \\
\hline Caffeine & 3.84 & 4.35 & 4.84 & 5.32 & 5.81 \\
\hline \multicolumn{6}{|c|}{ Tablets composition (mg/tablet) } \\
\hline Paracetamol & 240.0 & 270.0 & 300.0 & 330.0 & 360.0 \\
\hline Caffeine & 24.0 & 27.0 & 30.0 & 33.0 & 36.0 \\
\hline Lactose & 146.0 & 113.0 & 80.0 & 47.0 & 14.0 \\
\hline Cornstarch & \multirow{5}{*}{210.0} & \multirow{5}{*}{210.0} & \multirow{5}{*}{210.0} & \multirow{5}{*}{210.0} & \multirow{5}{*}{210.0} \\
\hline Silicon dioxide & & & & & \\
\hline PVP & & & & & \\
\hline Talcum & & & & & \\
\hline $\begin{array}{l}\text { Magnesium } \\
\text { stearate }\end{array}$ & & & & & \\
\hline Tablet weight & 620.0 & 620.0 & 620.0 & 620.0 & 620.0 \\
\hline
\end{tabular}

Calibration samples: levels 1-2-3-4-5; Validation samples: levels 2-3-4

TABLE 2. The matrix of experimental design uset for calibration set

\begin{tabular}{|c|c|c|c|c|c|c|c|}
\hline $\begin{array}{l}\text { Exp } \\
\text { Name }\end{array}$ & $\begin{array}{l}\text { Run } \\
\text { Order }\end{array}$ & $\mathbf{X 1}$ & $\mathbf{X 2}$ & $\begin{array}{l}\text { Exp } \\
\text { Name }\end{array}$ & $\begin{array}{l}\text { Run } \\
\text { Order }\end{array}$ & X1 & X2 \\
\hline N1 & 9 & 38.71 & 3.87 & N15 & 13 & 58.06 & 4.84 \\
\hline N2 & 26 & 43.55 & 3.87 & N16 & 25 & 38.71 & 5.32 \\
\hline N3 & 16 & 48.39 & 3.87 & N17 & 24 & 43.55 & 5.32 \\
\hline N4 & 21 & 53.23 & 3.87 & N18 & 17 & 48.39 & 5.32 \\
\hline N5 & 11 & 58.06 & 3.87 & N19* & 4 & 53.23 & 5.32 \\
\hline N6 & 15 & 38.71 & 4.35 & N20 & 7 & 58.06 & 5.32 \\
\hline N7* & $\mathbf{8}$ & 43.55 & 4.35 & N21 & 28 & 38.71 & 5.81 \\
\hline N8 & $\mathbf{6}$ & 48.39 & 4.35 & N22 & 1 & 43.55 & 5.81 \\
\hline N9 & $\mathbf{2 7}$ & 53.23 & 4.35 & N23 & 3 & 48.39 & 5.81 \\
\hline N10 & $\mathbf{2 3}$ & 58.06 & 4.35 & N24 & 18 & 53.23 & 5.81 \\
\hline N11 & $\mathbf{1 4}$ & 38.71 & 4.84 & N25 & 22 & 58.06 & 5.81 \\
\hline N12 & $\mathbf{2 0}$ & 43.55 & 4.84 & N26 & 12 & 48.39 & 4.84 \\
\hline N13* & $\mathbf{2}$ & 48.39 & 4.84 & N27 & 19 & 48.39 & 4.84 \\
\hline N14 & 10 & 53.23 & 4.84 & N28 & 5 & 58.06 & 4.84 \\
\hline
\end{tabular}

X1 - paracetamol concentration ( $\mathrm{mg} /$ tablet); X2 - caffeine concentration (mg/tablet); * - validation samples

$120 \%$ of the targeted tablet composition, which was considered the formulation containing $30.0 \mathrm{mg}$ caffeine $(4.84 \%, \mathrm{w} / \mathrm{w})$ and $300.0 \mathrm{mg}$ paracetamol (48.39\%, w/w). Cornstarch, PVP, talc and colloidal silicon dioxide were kept constant at a weight of 210 $\mathrm{mg}(33 \%, \mathrm{w} / \mathrm{w})$ in all formulations. At the same time, the filler (lactose) was used in variable ratios, such as to maintain a tablet weight of $620 \mathrm{mg}$. According to the generated design of experiment, the calibration set consisted of 28 formulations corresponding to five levels of each API (paracetamol and caffeine), respectively $80,90,100,110$ and $120 \%$ of the targeted dosage. In Table 2 is presented the composition of the calibration set.
Three independent series ( 1 series/day and 3 different days) at 3 different levels (corresponding to 90,100 and $110 \%$ of the targeted API content, for both paracetamol and caffeine, formulations N7, N13, N19 from Table 2) were prepared for validation purpose. Four independent formulations were prepared and analysed for each concentration level (12 formulations/day and a total of 36 formulations).

\section{NIR spectra recording}

The NIR spectrometer from Bruker Optics, Germany, (MPA analyser) with indium gallium arsenide (InGaAs) detector and in transmission sampling configuration for tablets were used for spectra recording. Opus 6.5 software (Bruker Optics, Germany) acquired transmittance spectra from 20 different tablets for each batch, from all calibration and validation batches. Each spectrum was an average of 32 integrated scans over the spectra range 12500 to $4000 \mathrm{~cm}-1$, and registered with a resolution of $16 \mathrm{~cm}-1$. Blank spectrum was recorded and subtracted before the integration.

\section{NIR data processing}

To develop the multivariate calibration method, both unprocessed and pre-processed spectra were used in combination with the spectral range $9000-4000 \mathrm{~cm}-1$ for paracetamol, and $6200-4100 \mathrm{~cm}-1$ for caffeine, respectively. The pre-processing methods used were as follows: straight line subtraction (SLS), minimum maximum normalisation ( $\mathrm{mMN}$ ), constant offset elimination (COE), first derivative (FD) standard normal variate (SNV), multiplicative scattering correction (MSC), and second derivative (SD). Moreover, combinations of two pre-processing methods (as FD+MSC, FD+SNV, FD+SLS) were also evaluated to develop calibration models.

\section{Opus Quant 6.5 software was also used for} multivariate calibrations and the development of prediction models. Partial least squares (PLS) were used as the regression method. Selection of the optimal number of PLS factors was carried out by cross-validation based on leave-one-out procedure.

The plot of the root mean square error of crossvalidation (RMSECV) versus the number of PLS factors was used to select the optimal number of PLS factors, while the values of RMSECV and bias were the basis for the selection of the best models. 


\section{NIR method validation}

In order to be suitable for routine analysis of tablets in pharmaceutical, the validation of the developed NIR method was performed. For this purpose, validation parameters recommended by the International Conference of Harmonization (ICH), FDA and EMA guidelines regarding validation of analytical methods were determined, i.e. linearity, precision

(repeatability, intermediate precision) and accuracy [ ]. Microsoft Excel 2010 (Microsoft Corporation, USA) were used to perform the calculations of validation parameters.

Accuracy profiles and external validation samples were used to evaluate the predictive performance of models. The statistical methodology used in this method consists in the use of tolerance intervals and allows predicting the region where each future result has a probability to fall, which the analyst defines. The accuracy profile takes into account the total error, accuracy being the expression of the sum of the trueness (systematic error, expressed as bias) and precision (random error, expressed as a standard deviation), and meets the ICH Q2 (R1) guideline requirements $[25,26]$.

\section{RESULTS AND DISCUSSION}

\section{Spectral investigation and models selection}

The NIR reflectance spectra of the tablets from the calibration set are presented in Figure 1. Wavelength range selection was performed first to adequately construct the calibration models, based on those spectral regions where the information is related to the variation in the API concentration. Thus, the spectral region below $4000 \mathrm{~cm}-1$ was first eliminated from the analysis, being characterised by high background noise [ ]. Further, the selected spectral region was $9000-4000 \mathrm{~cm}-1$ for paracetamol and $6200-4100 \mathrm{~cm}-1$ for caffeine. These regions present significant differences between absorption bands, as previously reported [24].

\section{Model selection and development}

A high number of calibration models were developed for both paracetamol and caffeine, by performing PLS regression on un-processed as well as pre-processed spectra. The calibration models resulted in this way are presented in Table 3, in terms of number of PLS factors, R2, RMSECV and bias. The selection of the model with best predictive capacity was based on the

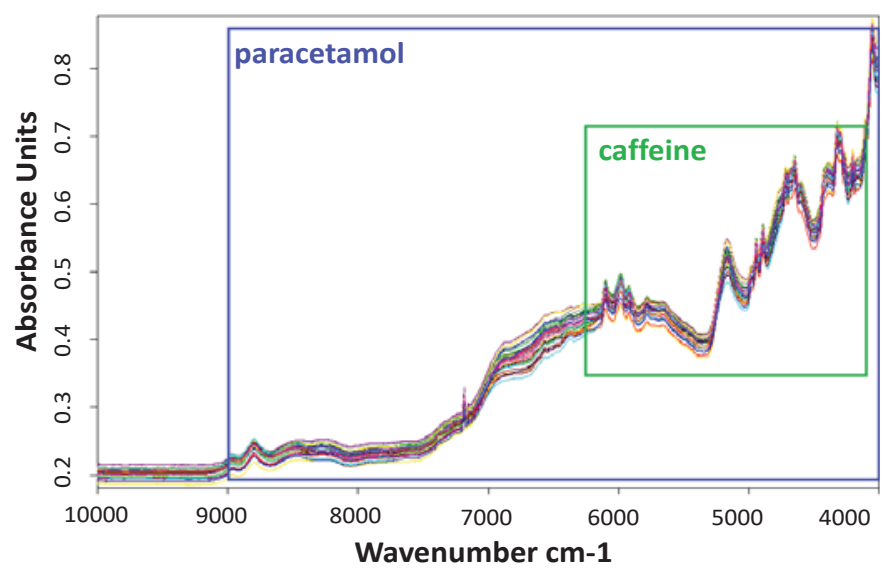

FIGURE 1. Reflectance spectrum of tablets recorded at a resolution of $8 \mathrm{~cm}-1$ for calibration set. The highlighted blue areas define the spectral ranges selected for paracetamol and the green area define the spectral ranges selected for caffeine

number of PLS factors, and the values of RMSECV and bias.

As seen in Table 3, for paracetamol, the models developed by applying pre-processing algorithms had in general better predicative ability than the model generated using un-processed spectra. Thus, for the explored calibration models, the number of PLS factors varied between 2 and 5, the RMSECV was lower than $3 \%$ and bias was below 0.410. A model based on a combination of spectral pre-processing algorithms, i.e. FD+SNV, was finally selected, because it had the best predictive capacity (lowest RMSECV) at the lowest number of factors [2].

For caffeine, as shown in Table 3, the calibration models were based on a higher number of PLS factors, i.e. between 7 and 9. A model based on a combination of pre-processing methods, FD and MSC, was selected for further method validation, based on its low RMSECV and bias values.

\section{Method validation}

Validation of NIR methods for simultaneous assay of paracetamol and caffeine was performed using tablets with an active content ranging from 90 to $110 \%$ of the targeted paracetamol and caffeine concentration in tablets, following the described validation protocol. The linear profile, obtained through representation of the calculated concentrations versus theoretical concentrations of validation samples, is presented in Figure 2. As seen in Figure 2(A), the linearity of the method for paracteamol assay is good, as R2 value is 0,9925 and slope is close to 1 . The linearity of the model developed for caffeine assay is also good, the 


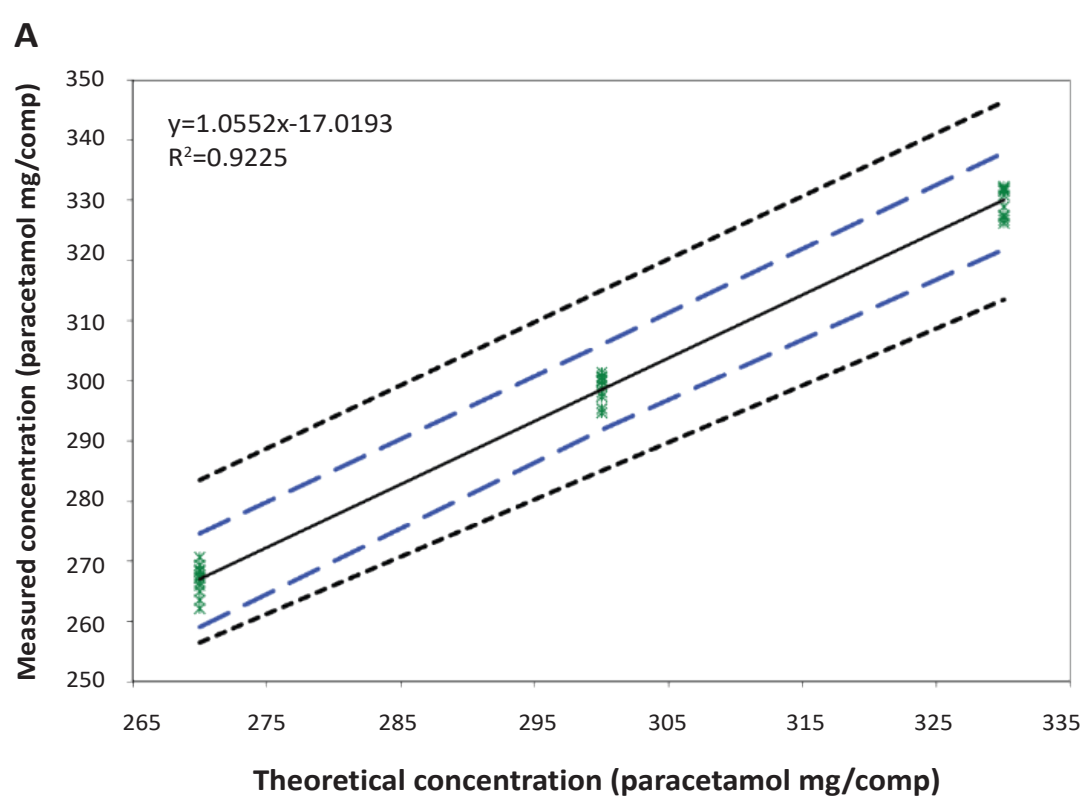

B

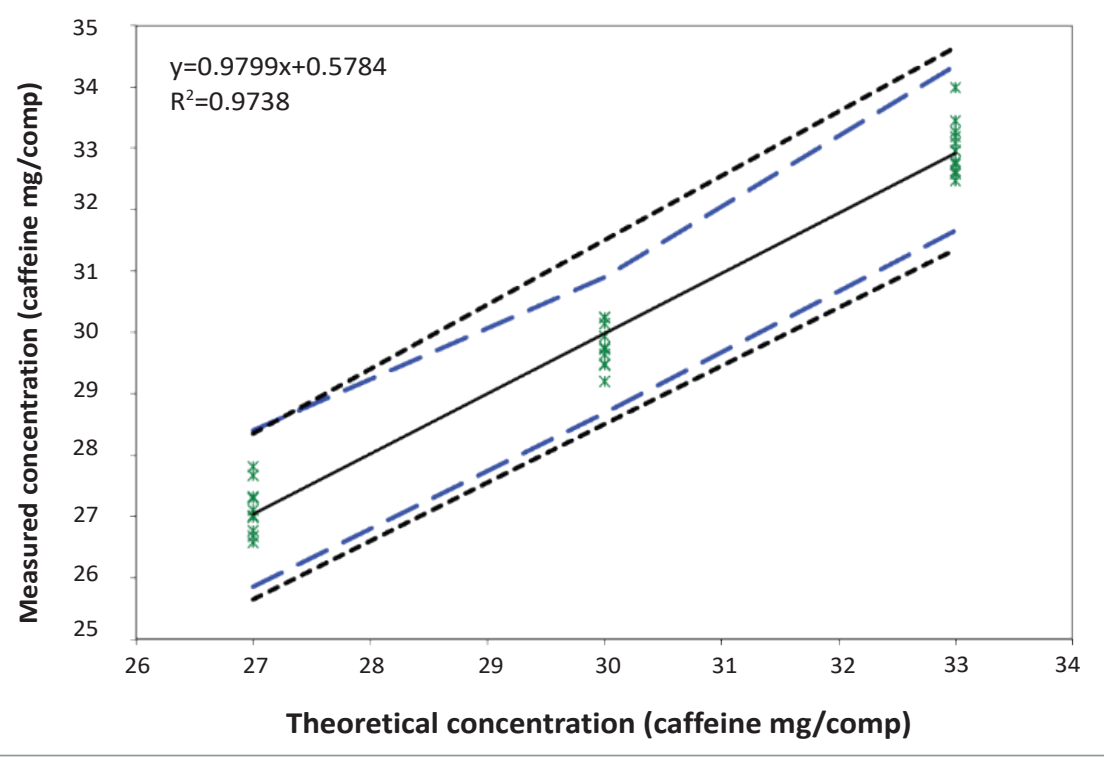

FIGURE 2. Linearity profile of NIR - chemometic methods for the the assay of paracetamol (A) and caffeine (B) in tablets. and caffeine, respectively). The method precision was evaluated by calculating two parameters, intermediate precision (repeatability over different days) and repeatability (intra-day precision). According to obtained results, these parameters have satisfactory values for both drugs, for all the concentration levels from the validation set.

The accuracy profiles were plotted in Figure 3 for both paracetamol (A) and caffeine (B). Because the methods are proposed to determine the APIs in pharmaceutical products, the acceptance limits were set at \pm $5 \%$. According to the validation methodology followed in this study, the $\beta$-expectation tolerance limits should not exceed the acceptance limits, for a good accuracy of the method. As is presented in Figure 3(A) and Table 4 , the $\beta$-expectation tolerance limits are included within the acceptance limits in the case of paracetamol, so the selected model is well fitted for the assay of paracetamol within the established concentration domain.

On the other hand, in the case of caffeine, for the lowest concentration in the validation set, i.e. $27 \mathrm{mg} / \mathrm{tablet}$, the $\pm 5 \%$
R2 value being 0,9738 and slope close to 1 , as shown in Figure 2(B).

Further, the methods developed for paracetamol and caffeine assay were validated in for trueness, accuracy precision and linearity and the results are presented in Table 4. The trueness was evaluated by calculating the relative bias (\%) and the recovery (\%), for each drug and concentration level in the validation set.

According to obtained results presented in Table 4, the relative bias was lower than $1.2 \%$ in all cases, and the recovery was very close to $100 \%$ (between $98.82 \%$ and $99.98 \%$ and $99.32 \%$ and $100.47 \%$, for paracetamol acceptance limits are exceeded by the $\beta$-expectation tolerance limits, so the proposed method will be inaccurate for the assay of caffeine in tablets with a caffeine content lower than $28 \mathrm{mg} /$ tablet. However, a caffeine content lower than $28 \mathrm{mg} /$ tablet will not be found normally in routine applications, because the caffeine content of tablets meeting the European Pharmacopoeia requirements in terms of uniformity of content should be between $28.5 \mathrm{mg}$ and $31.5 \mathrm{mg}$.

According to the results presented in Figure 2, Figure 3 and Table 4, the NIR-chemometric methods proposed for the simultaneous assay of paracetamol and 
TABLE 3. Statistical parameters and number of PLS factors for different models proposed for paracetamol and caffeine assay in tablets

\begin{tabular}{|c|c|c|c|c|c|c|c|c|c|c|c|}
\hline \multicolumn{12}{|l|}{ Paracetamol } \\
\hline Model & a & b & c & d & e & $f$ & g & h & $\mathbf{i}$ & $\mathbf{j}^{*}$ & k \\
\hline Pre-treatment & None & COE & SLS & SNV & $\mathrm{mMN}$ & MSC & FD & SD & $\mathrm{FS}+\mathrm{SLS}$ & $\mathrm{FD}+\mathrm{SNV}$ & $\mathrm{FD}+\mathrm{MSC}$ \\
\hline $\begin{array}{c}\text { Spectral range } \\
\text { selected } \\
(\mathrm{cm}-1)\end{array}$ & \multicolumn{11}{|l|}{$9000-4000$} \\
\hline $\begin{array}{c}\text { Number of PLS } \\
\text { factors }\end{array}$ & 5 & 5 & 4 & 3 & 5 & 3 & 3 & 5 & 3 & 2 & 2 \\
\hline R2 & 0.9955 & 0.9955 & 0.9952 & 0.9952 & 0.9958 & 0.9952 & 0.9951 & 0.9953 & 0.9952 & 0.9955 & 0.9950 \\
\hline RMSECV (\%) & 2.74 & 2.74 & 2.83 & 2.82 & 2.62 & 2.82 & 2.83 & 2.77 & 2.81 & 2.72 & 2.87 \\
\hline Bias (\%) & 0.265 & 0.303 & 0.311 & 0.232 & 0.275 & 0.232 & 0.357 & 0.102 & 0.362 & 0.376 & 0.405 \\
\hline \multicolumn{12}{|l|}{ Caffeine } \\
\hline Model & a & b & $c^{*}$ & d & e & $f$ & g & $\mathrm{h}$ & $\mathbf{i}$ & j & $\mathrm{k}^{*}$ \\
\hline Pre-treatment & None & $\mathrm{COE}$ & SLS & SNV & $\mathrm{mMN}$ & MSC & FD & SD & $\mathrm{FS}+\mathrm{SLS}$ & FD+SNV & $\mathrm{FD}+\mathrm{MSC}$ \\
\hline $\begin{array}{c}\text { Spectral range } \\
\text { selected } \\
(\mathrm{cm}-1)\end{array}$ & \multicolumn{11}{|l|}{$6200-4100$} \\
\hline $\begin{array}{c}\text { Number of PLS } \\
\text { factors }\end{array}$ & 9 & 9 & 9 & 9 & 9 & 7 & 9 & 10 & 8 & 9 & 9 \\
\hline R2 & 0.907 & 0.9071 & 0.9295 & 0.9331 & 0.925 & 0.938 & 0.949 & 0.9554 & 0.9476 & 0.9573 & 0.9588 \\
\hline RMSECV (\%) & 1.32 & 1.26 & 1.18 & 1.16 & 1.21 & 1.13 & 1.05 & 1 & 1.06 & 0.985 & 0.973 \\
\hline Bias (\%) & 0.00048 & -0.0001 & -0.00742 & -0.0020 & -0.0169 & -0.00157 & 0.0056 & -0.0015 & -0.00841 & -0.0039 & -0.0025 \\
\hline
\end{tabular}

* selected model for validation of the methods

TABLE 4. Validation results of NIR method for paracetamol and caffeine assay in tablets

\begin{tabular}{|c|c|c|c|c|c|c|c|}
\hline \multicolumn{8}{|l|}{ Paracetamol } \\
\hline \multirow[b]{2}{*}{$\begin{array}{l}\text { Concentration } \\
\text { level } \\
\text { (paracetamol) }\end{array}$} & \multirow{2}{*}{$\begin{array}{l}\text { Mean } \\
\text { paracetamol } \\
\text { content }(\mathrm{mg} / \\
\text { tablet) }\end{array}$} & \multicolumn{2}{|l|}{ Trueness } & \multicolumn{2}{|l|}{ Precision } & \multicolumn{2}{|l|}{ Accuracy } \\
\hline & & $\begin{array}{l}\text { Relative } \\
\text { bias (\%) }\end{array}$ & $\begin{array}{c}\text { Recovery } \\
(\%)\end{array}$ & $\begin{array}{c}\text { Repeatability (RSD } \\
\%)\end{array}$ & $\begin{array}{c}\text { Intermediate } \\
\text { precision (RSD } \\
\% \text { ) }\end{array}$ & $\begin{array}{l}\text { Relative } \\
\text { tolerance } \\
\text { limits (\%) }\end{array}$ & $\begin{array}{c}\text { Tolerance limits } \\
\text { (mg/tablet) }\end{array}$ \\
\hline 270 & 266.82 & -1.179 & 98.82 & 0.574 & 1.104 & $\begin{array}{c}{[-4.08} \\
1.72] \\
\end{array}$ & [259.06 274.57] \\
\hline 300 & 298.93 & -0.358 & 99.64 & 0.336 & 0.809 & $\begin{array}{c}{[-2.71} \\
2.00] \\
\end{array}$ & [291.86 305.98] \\
\hline 330 & 329.95 & -0.016 & 99.98 & 0.258 & 0.830 & $\begin{array}{r}{[-2.45} \\
2.42]\end{array}$ & [321.89 383.00] \\
\hline \multicolumn{8}{|l|}{ Caffeine } \\
\hline \multirow[b]{2}{*}{$\begin{array}{l}\text { Concentration } \\
\text { level (caffeine) }\end{array}$} & \multirow[b]{2}{*}{$\begin{array}{l}\text { Mean caffeine } \\
\text { content (mg/ } \\
\text { tablet) }\end{array}$} & \multicolumn{2}{|l|}{ Trueness } & \multicolumn{2}{|l|}{ Precision } & \multicolumn{2}{|l|}{ Accuracy } \\
\hline & & $\begin{array}{l}\text { Relative } \\
\text { bias (\%) }\end{array}$ & $\begin{array}{c}\text { Recovery } \\
(\%)\end{array}$ & $\begin{array}{c}\text { Repeatability (RSD } \\
\%)\end{array}$ & $\begin{array}{c}\text { Intermediate } \\
\text { precision (RSD } \\
\% \text { ) }\end{array}$ & $\begin{array}{l}\text { Relative } \\
\text { tolerance } \\
\text { limits (\%) } \\
\end{array}$ & $\begin{array}{c}\text { Tolerance limits } \\
\text { (mg/tablet) }\end{array}$ \\
\hline 27.00 & 27.13 & 0.471 & 100.47 & 1.324 & 1.397 & $\begin{array}{c}{[-4.21} \\
5.15] \\
\end{array}$ & [ 25.85 28.39] \\
\hline 30.00 & 29.80 & -0.678 & 99.32 & 1.338 & 1.647 & $\begin{array}{c}{[-4.39} \\
3.04] \\
\end{array}$ & [28.69 30.92] \\
\hline 33.00 & 33.01 & 0.021 & 100.02 & 1.373 & 1.618 & $\begin{array}{c}{[-4.07} \\
4.11] \\
\end{array}$ & [31.65 34.35] \\
\hline
\end{tabular}

caffeine in tablets has reproducibility, good linearity and accuracy profile, for routine analysis of the two active ingredients in tablets. Thus, the method will provide results with good accuracy for tablets containing $270 \mathrm{mg}$ to $330 \mathrm{mg}$ paracetamol, and $28 \mathrm{mg}$ to $33 \mathrm{mg}$ caffeine, respectively. 


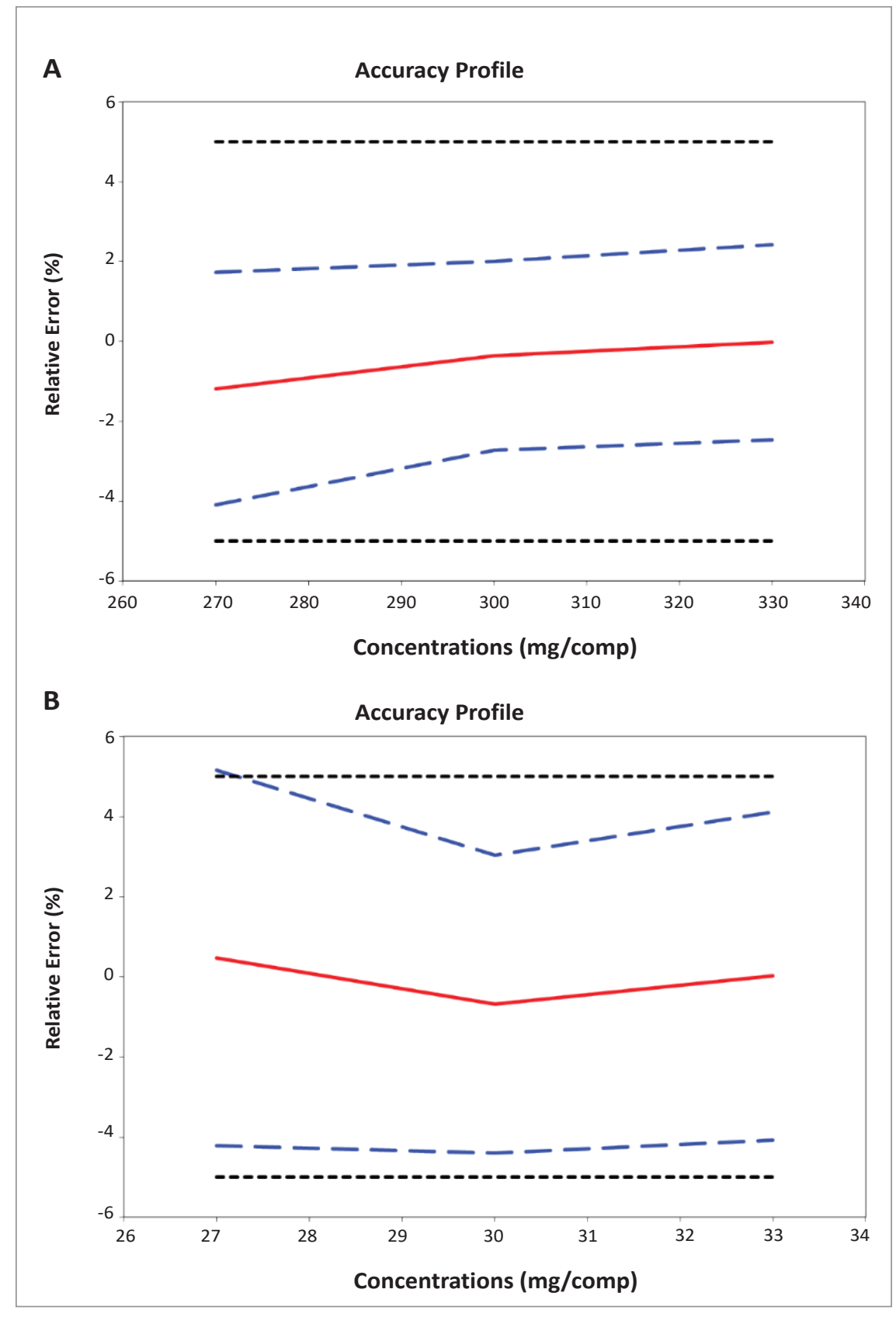

FIGURE 3. Accuracy profile of the NIR-chemometic methods for the assay of paracetamol $(A)$ and caffeine $(B)$ in tablets

TABLE 5. Paracetamol and caffeine determination by NIR validated method and HPLC reference method

\begin{tabular}{|c|c|c|c|c|}
\hline & \multicolumn{2}{|l|}{ Paracetamol } & \multicolumn{2}{c|}{ Caffeine } \\
\hline Method & NIR & HPLC & NIR & HPLC \\
\hline $\begin{array}{c}\text { Theoretic } \\
\text { concentration } \\
\text { (mg) }\end{array}$ & 300.0 & 300.0 & 30.00 & 30.00 \\
\hline Found (mg) & 298.92 & 298.65 & 29.89 & 29.59 \\
\hline Recovery (\%) & 99.64 & 99.55 & 99.62 & 98.64 \\
\hline SD & 1.99 & 2.30 & 0.37 & 0.83 \\
\hline t-value & 0.221 & 0.788 & 4.35 & N20 \\
\hline p-value & $\mathbf{0 . 8 3 0}$ & 0.448 & 4.35 & N22 \\
\hline
\end{tabular}
content in tablets.

\section{Method application}

The validated non-destructive NIR-chemometric methods were applied to control samples in order to predict their content in terms of paracetamol and caffeine. The active ingredients concentrations' were also determined by means of reference HPLC methods as previously described [24], and the results are presented in Table 5 . As shown in this table, the recovery exceeded $99 \%$ by both methods for paracetamol, while in the case of caffeine the recovery was higher by NIR method than by reference method. Moreover, no statistical significant difference was found between the two means at $95 \%$ confidence limit, as shown by the values of statistical parameters.

\section{CONCLUSIONS}

NIR-chemometric methods were developed and validated for rapid chemical characterisation of tablets in terms of APIs (paracetamol and caffeine) content. NIR transmission spectra recorded on intact tablets were pre-processed to remove the variation not related to APIs concentrations and PLS regressions were developed to relate the spectral information with the chemical composition. The resulted models were validated in terms of linearity, trueness, precision and accuracy, for an active content of 90,100 and $110 \%$ of the targeted paracetamol and caffeine tablet content. Finally, the NIR chemometric methods were used for simultaneous assay of paracetamol and caffeine in intact tablets, the results being similar with those obtained by conventional HPLC methods. As a result, the method presented in this paper can be used for the determination of paracetamol and caffeine in tablets without any sample preparation, thus being a cost and time effective alternative to laborious HPLC methods routinely used for the determination of drug 


\section{Acknowledgement}

This work was supported by a grant of the Romanian National Authority for Scientific Research and Innovation, CNCS - UEFISCDI, project number PN-IIIP2-2.1-BG-2016-0201.

\section{Funding}

This work was supported by a grant of the Romanian National Authority for Scientific Research and Innovation, CNCS - UEFISCDI, project number PN-IIIP2-2.1-BG-2016-0201.

\section{Conflict of interest: none declared}

\section{REFERENCES}

1. De Beer T, Burggraeve A, Fonteyne M, Saerens L, Remon JP, Vervaet C. Near infrared and Raman spectroscopy for the in-process monitoring of pharmaceutical production processes. Int J Pharm. 2011;417(1-2):32-47.

2. Monograph 2.2.40. Near-infrared spectroscopy, in European Pharmacopoeia 10 edition, 2021.

3. Porfire A, Rus L, Vonica AL, Tomuta I. High-throughput NIRchemometric methods for determination of drug content and pharmaceutical properties of indapamide powder blends for tabletting. J Pharm Biomed Anal. 2012;70:301-9.

4. Bakri B, Weimer M, Hauck G, Reich G. Assessment of powder blend uniformity: Comparison of real-time NIR blend monitoring with stratified sampling in combination with HPLC and at-line NIR Chemical Imaging. Eur J Pharm Biopharm. 2015;97(Pt A):78-89

5. Ingle PD, Christian R, Purohit P, Zarraga V, Handley E, Freel K, Abdo S. Determination of Protein Content by NIR Spectroscopy in Protein Powder Mix Products. J AOAC Int. 2016;99(2):360-3.

6. Miyano T, Kano M, Tanabe H, Nakagawa H, Watanabe T, Minami H. Spectral fluctuation dividing for efficient wavenumber selection: application to estimation of water and drug content in granules using near infrared spectroscopy. Int J Pharm. 2014 20;475(12):504-13.

7. Barimani S, Kleinebudde P. Monitoring of tablet coating processes with colored coatings. Talanta. 2018 Feb 1;178:686-697.

8. Goodwin DJ, van den Ban S, Denham M, Barylski I. Real time release testing of tablet content and content uniformity. Int J Pharm. 2018;537(1-2):183-192.

9. Mbinze JK, Sacré PY, Yemoa A, et al. Development, validation and comparison of NIR and Raman methods for the identification and assay of poor-quality oral quinine drops. J Pharm Biomed Anal. 2015;111:21-27.

10. Quintelas C, Mesquita DP, Lopes JA, Ferreira EC, Sousa C. Nearinfrared spectroscopy for the detection and quantification of bacterial contaminations in pharmaceutical products. Int J Pharm. 2015;492(1-2):199-206.

11. Porfire A, Tomuta I, Tefas L, Leucuta SE, Achim M. Simultaneous quantification of I- $\alpha$-phosphatidylcholine and cholesterol in liposomes using near infrared spectrometry and chemometry. J Pharm Biomed Anal. 2012;63:87-94.

12. Porfire A, Muntean D, Achim M, Vlase L, Tomuta I. Simultaneous quantification of simvastatin and excipients in liposomes using near infrared spectroscopy and chemometry. J Pharm Biomed Anal. 2015; 107:40-49.

13. De Beer T, Burggraeve A, Fonteyne M, Saerens L, Remon JP, Vervaet C. Near infrared and Raman spectroscopy for the in-process monitoring of pharmaceutical production processes. Int J Pharm. 2011;417(1-2):32-47.

14. Casian T, Reznek A, Vonica-Gligor AL, Van Renterghem J, De Beer T, Tomuță I. Development, validation and comparison of near infrared and Raman spectroscopic methods for fast characterization of tablets with amlodipine and valsartan. Talanta. 2017;167:333-343.
15. Teixeira KSS, da Cruz Fonseca SG, de Moura LCB, et al. Use of chemometrics to compare NIR and HPLC for the simultaneous determination of drug levels in fixed-dose combination tablets employed in tuberculosis treatment. J Pharm Biomed Anal. 2018;149:557-563.

16. Karande AD, Heng PW, Liew CV. In-line quantification of micronized drug and excipients in tablets by near infrared (NIR) spectroscopy: Real time monitoring of tabletting process. Int J Pharm. 2010;396(1-2):63-74.

17. Wahl PR, Fruhmann G, Sacher S, Straka G, Sowinski S, Khinast JG. PAT for tableting: inline monitoring of API and excipients via NIR spectroscopy. Eur J Pharm Biopharm. 2014;87(2):271-278.

18. Porfire A, Filip C, Tomuta I. High-throughput NIR-chemometric methods for chemical and pharmaceutical characterization of sustained release tablets. J Pharm Biomed Anal. 2017;138:1-13.

19. Blanco M, Alcalá M. Content uniformity and tablet hardness testing of intact pharmaceutical tablets by near infrared spectrposcopy. A contribution to process analytical technologies. Analytica Chimica Acta, 2006;557:353-359.

20. Tomuta I, Rus L, lovanov R, Rus LL. High-throughput NIRchemometric methods for determination of drug content and pharmaceutical properties of indapamide tablets. J Pharm Biomed Anal. 2013;84:285-292.

21. Tomuta I, lovanov R, Bodoki E, Vonica L. Development and validation of NIR-chemometric methods for chemical and pharmaceutical characterization of meloxicam tablets. Drug Dev Ind Pharm. 2014;40(4):549-559.

22. Peeters E, Tavares da Silva AF,Toiviainen M, Van Renterghem J, Vercruysse J, Juuti M, Lopes JA, De Beer T, Vervaet C, Remonet JP. Assessment and prediction of tablet properties using transmission and backscattering Raman spectroscopy and transmission NIR spectroscopy. Asian Journal of Pharmaceutical Sciences 2016;11(4):547-558.

23. Kandpal L, Tewari JC, Gopinathan N, Stolee JA, Strong R, Boulas P, Cho B. Quality assessment of pharmaceutical tablet samples using Fourier transform near infrared spectroscopy and multivariate analysis. Infrared Physics \& Technology. 2017; 85:300-306.

24. Muntean DM, Alecu C, Tomuta I. Simultaneous quantification of paracetamol and caffeine in powder blends for tabletting by NIR-chemometry. Journal of Spectroscopy. 2017:7160675.

25. . ICH Q2(R1), 2005. Validation of Analytical Procedures: Text and Methodology. Available at: http://www.ich.org/ products/ guidelines/quality/quality-single/article/validation-of-analyticalprocedures-text-and-methodology.html.

26. . Hubert P, Nguyen-Huu JJ, Boulanger B, et al. Harmonization of strategies for the validation of quantitative analytical procedures. A SFSTP proposal--Part I. J Pharm Biomed Anal. 2004;36(3):579-586.

27. . Z Xiaobo Z, Jiewen Z, Povey MJ, Holmes M, Hanpin M. Variables selection methods in near-infrared spectroscopy. Anal Chim Acta. 2010;667(1-2):14-32. 